\title{
Entre sangue e a afinidade: dilemas de parentesco em casos de abuso sexual intrafamiliar no Amazonas, Brasil ${ }^{1}$
}

\author{
Natã Souza Lima ${ }^{2}$ \\ Raquel Wiggers 3 \\ Universidade Federal do Amazonas
}

Resumo: A partir de casos emblemáticos ocorridos no Amazonas, em famílias com trânsito entre o rural e o urbano, percebemos uma tensão recorrente entre consanguinidade e afinidade, a partir de atos sexuais entre adultos e crianças com vínculos de parentesco, classificados em contextos de punição como "abusos sexuais", nos eixos de relação "avô-neto/a" e "padrasto-enteado/a. Desse contexto etnográfico, propomos analisar trocas de fluidos (sangue, sêmen) entre adultos e crianças, a partir da diferença do status de parentesco, das vítimas em relação aos agressores, refletindo sobre (1) o que aproxima e distancia parentes e (2) como tais atos produzem um novo status nos vínculos de parentesco.

Palavras-chave: parentesco; violência sexual; incesto; fluidos corporais.

${ }^{1}$ Uma prévia deste artigo foi apresentada no Grupo de Trabalho "O que carrega o sangue? Elaborações em torno do sangue e seus potenciais produtivos”, em 2019, durante a XIII Reunião de Antropologia do Mercosul, em Porto Alegre, RS. Agradecemos os debates provocados pela leitura de Juliana Caruso, Flávio Tarnovski, Carolina Portela e Marisol Marini.

2 Doutorando no Programa de Pós-graduação em Antropologia Social da Universidade Federal do Amazonas (PPGAS/ UFAM). Pesquisador do Azulilás - Núcleo de Estudos em Gênero, Famílias, Conflitos e Sexualidades (PPGAS/DAN/ UFAM)

3 Professora do Programa de Pós-graduação em Antropologia Social da Universidade Federal do Amazonas (PPGAS/ UFAM). Coordenadora do Azulilás - Núcleo de Estudos em Gênero, Famílias, Conflitos e Sexualidades (PPGAS/DAN/ UFAM) 


\title{
Between blood and affinity: kinship dilemmas in cases of intrafamily sexual abuse in Amazonas, Brazil
}

\begin{abstract}
From emblematic cases that occurred in Amazonas, in families with flow rural and the urban, understand a recurring tension between consanguinity and affinity, from sexual acts between adults and children with kinship ties, classified in contexts of punishment as "sexual abuse", in the "grandfather-grandson" and "stepfather-stepson" relationship axes. From this ethnographic context, we propose to analyze fluid exchanges (blood, semen) between adults and children, based on the difference of kinship, of the victims in relation to the aggressors, reflecting on (1) what approximates and distances parents and (2) how such acts produce a new status in kinship.
\end{abstract}

Keywords: kinship; sexual violence; incest; body fluids.

\section{Entre sangre y afinidad: dilemas de parentesco en casos de abuso sexual intrafamiliar en Amazonas, Brasil}

Resumen: A partir de casos emblemáticos que ocurrieron en Amazonas, en familias con relación entre lo rural y lo urbano, notamos una tensión recurrente entre la consanguinidad y la afinidad, de los actos sexuales entre adultos y niños con vínculos de parentesco, clasificados en contextos de justicia como "abuso sexual", en los ejes de relación "abuelo-nieto" y "padrastro-hijastro". Desde este contexto etnográfico, proponemos analizar los intercambios de fluidos (sangre, semen) entre adultos y niños, en función de la diferencia de estado de parentesco, de las víctimas en relación con los agresores, reflexionando sobre (1) qué aproxima y distancia a los familiares y (2) cómo tales actos producen un nuevo estatus en los lazos de parentesco.

Palabras clave: parentesco; violencia sexual; incesto fluidos corporales. 
A violência sexual é uma categoria elaborada historicamente como problema social, que inclui diferentes tipos de violação, atravessadas por gênero, geração, raça e classe social. O abuso sexual é a violência sexual contra crianças e adolescentes, tendo, geralmente um adulto como agressor. Essa categoria é subdividida entre "abuso sexual extrafamiliar", quando a violação não envolve parentes ou pessoas com relação de moradia, e "abuso sexual intrafamiliar", quando a violação ocorre entre parentes.

O "abuso sexual intrafamiliar" é o tipo de violência sexual mais recorrente no Brasil, segundo dados do Ministério da Saúde (2018) e Ministério da Mulher, Família e Direitos Humanos (2020), representando 80\% das denúncias de casos totais, e tendo como agressores, primordialmente, padrastos, pais e avôs. Dados do Serviço de Atendimento às Vítimas de Violência Sexual do Amazonas (SAVVIS), dos últimos seis anos, apontam a recorrência de 90\% dos casos de violência sexual, cometidos entre parentes. Contudo, as violências sexuais em família, têm baixa resolução judicial o que significaria a punição dos agressores, propiciando o afastamento das relações familiares e de moradia.

Além dos muitos problemas na ação estatal, ponderamos que a ineficiência da ação do Estado em prevenir, punir e combater aquilo que define como "violência sexual", é atravessada pelo modo de como se estruturam as relações de parentesco. Nesse sentido, nossa hipótese é de que, em relação às violências sexuais intrafamiliares, o Estado e seus agentes operam não apenas com normas legais, mas compartilham com as famílias que protegem seus parentes agressores, noções sobre a manutenção da família, principalmente, dos vínculos de consanguinidade.

O distanciamento das relações familiares, seja por meio da punição na justiça ou afastamento do parente agressor, parece ser o caminho mais óbvio após um abuso sexual intrafamiliar. Porém esse é um crime difícil de ser investigado e punido. Quando há vínculo de parentesco entre agressor e vítima, essas dificuldades são maiores, pois há uma tendência de aglutinamento dos parentes em torno da proteção do sujeito agressor. Proteção, nesse caso, significa gerir coações em família para a retirada dos processos, faltar audiências, driblar laudos, entre outras estratégias que dificultam a elaboração de provas materiais que comprovem as violências.

Lopes Leitão (2016) é categórica ao afirmar que "a pena legal para quem pratica abuso sexual ou participa da exploração sexual contra crianças e adolescentes, no Brasil, é a reclusão. Isso [o risco da reclusão] traz um impacto nos comportamentos dos integrantes da família”.

No Amazonas, desde 2012, o Azulilás - Núcleo de Estudos em Gênero, Famílias, Conflitos e Sexualidades (PPGAS/DAN/UFAM) tem se dedicado a pesquisas sobre padrões de conflito e resolução familiar em casos de violência sexual, buscando compreender, por diferentes perspectivas as cenas de "abuso sexual" no Amazonas, através de documentos e casos empíricos obtidos em órgãos de Justiça e Assistência Social. Com pesquisadores em diferentes níveis de formação, concentrados em etnografar distintos pontos de vista - a partir da exploração sexual, da violência intrafamiliar, de mães de vítimas, de profissionais encarregados do atendimento às vítimas e dos autores da violência - temos buscado pensar 
sobre motivações, conflitos, poderes, desejos, e modelos de organização que são mobilizados em torno da violência sexual.

Os dados de referência para a discussão proposta neste texto, estão situados nesse contexto de pesquisa, e foram obtidos entre 2012 e 2016 através da pesquisa de Lima (2018), que compôs o "Observatório da Violência Sexual no Amazonas" 4 Os relatos foram obtidos a partir das reuniões do "Grupo de Autores”, um serviço de atendimento psicossocial para homens acusados de abuso sexual contra crianças e adolescentes. Esse grupo não tinha vínculo direto com a justiça (como pena alternativa), mas era realizado voluntariamente no Centro de Referência Especializado em Assistência Social de Manaus (CREAS). Todos os interlocutores eram voluntários no serviço, que funcionava no formato de um grupo de apoio mútuo, com participação de uma psicóloga voluntária.

A pesquisa envolveu acordos com os interlocutores sobre manter a identidade e características pessoais em sigilo. Os dados aqui narrados partem do consentimento dos participantes, mesmo que algumas falas sejam explicitamente violentas. As genealogias foram elaboradas a partir de rascunhos feitos junto com os participantes do "Grupo de Autores", e a partir de fichas preenchidas num momento de "triagem" 5 . Algumas adaptações foram feitas para fins da análise antropológica aqui proposta, mas sem uso de programas específicos, uma vez que era necessário manter ao máximo a integridade da elaboração conjunta e evidenciar os eixos onde ocorreram abusos sexuais intrafamiliares. Em todas as genealogias o ego será sempre o agressor.

Todos os homens ouvidos no âmbito do "Grupo de Autores", tiveram seus processos arquivados, principalmente porque os familiares que lhes acusavam, deixaram de comparecer às audiências.

Desses casos, classificados como "abusos sexuais intrafamiliares" no Amazonas, notamos que existe uma tensão, permeada de ambiguidades, entre relações de parentesco por consanguinidade e por afinidade, e a consideramos basilar para a recorrência de atos sexuais entre adultos e crianças com vínculos de parentesco.

A diferença do status das vítimas, como afins ou consanguíneos em relação aos agressores nos permitiu apontar as diferenças nos vínculos de parentesco, e partir disso, pensar como o abuso sexual intrafamiliar atua para (1) aproximar e distanciar parentes; e (2) como produz novos status na família, para vítimas e agressores. A diferença a qual nos referimos, não é apenas entre vítima e agressor, mas ao lugar de ambos na família, antes e após o abuso. Nesse sentido, a análise dos casos de "abuso sexual intrafamiliar”, nos parece um caminho possível para compreender padrões de organização familiar no Amazonas'.

Os dois casos aqui relatados foram construídos como paradigmáticos de abuso sexual intrafamiliar, e a partir de sujeitos em trânsito do norte ao centro

\footnotetext{
4 Projeto aprovado no Comitê de Ética em Pesquisa, Limites e Possibilidades: Uma aproximação da realidade de crianças e adolescentes em situação de violência sexual, CAAE 02463212.8.0000.5020.

5 A triagem era a primeira abordagem do serviço de atendimento feito pelo "Grupo de Autores", com levantamento da genealogia do agressor, dados sobre a violência, sobre o processo, entre outros.

${ }^{6}$ Várias discussões sobre poder e a posição dos homens, como sujeitos que têm acesso primordial à violência, poderiam ser discutidas aqui. A violência sexual, em suas múltiplas formas, é um crime que cruza diferentes matrizes explicativas. A desigualdade de poder nas relações de gênero é um fator preponderante para as taxas altas de violência sexual no Brasil, mas não é autoexplicativo. Essa desigualdade nas relações de força e poder (WIGGERS, 2000) é sustentada por modelos de organização familiar com especificidades regionais do Brasil, por lógicas de Estado e de seus agentes (LIMA, 2018), e uma série de problemas na efetivação de políticas públicas, como a escassez de abrigos para vítimas, falta de atendimento especializado em delegacias para escuta de mulheres e crianças vítimas de violência sexual, e os horários de funcionamento dos organismos de justiça e assistência social. Aqui, fazemos um esforço de traçar moralidades em torno de padrões familiares nos contextos de violência sexual no Amazonas, como uma perspectiva importante sobre esse tema.
} 
do Amazonas7, em Manaus, estamos destacando dois eixos: "padrastro-enteada" e "avô-neto/a".

\section{O caso Chefe}

Um homem cuja idade variava entre 50 e 60 anos, o tipo caboclo do Amazonas, pele morena, queimada pela vida de trabalho exposto ao Sol, cabelos negros lisos, estrutura muscular forte. Sempre usava calça de algodão, as vezes um jeans, com sapatos de couro e camisa de botão em cores neutras, variava no máximo entre verde ou azul escuro. Cordial, mas nada expansivo, um homem reconhecido socialmente como "sério".

Chefe era casado e tinha cinco filhos, e todos moravam em sua casa. Três filhas adultas, um filho adulto, uma filha adolescente.

Ele descrevia sua casa como seu local de moradia, com sua esposa e filhos. Sua casa agregava tanto suas filhas e filho, quanto cônjuges e netos. Era sem dúvida uma casa grande, da qual ele se orgulhava de ter construído. Duas de suas filhas adultas eram casadas e tinham filhos pequenos. Seu filho também era casado, policial militar, e não tinha filhos. Chefe tinha uma filha solteira com uma filha, que em alguns momentos ele nomeava como "filha de criação" e "neta de criação". Entre as ocupações profissionais da casa, mencionava apenas a do filho, policial militar.

Quando casou com sua esposa, ela já tinha uma filha, e ambos acordaram que a menina seria criada como filha de Chefe. Depois foram nascendo os outros quatro filhos de Chefe. Ele não falava muito das filhas adultas, mencionava com mais recorrência a filha adolescente, para quem pagava cursos, sobre quem relatava ter conflitos decorrentes de sua "rebeldia" e das preocupações com o vestibular.

Na medida que os filhos iam casando, Chefe aumentava a casa. Chegou a comprar dois terrenos vizinhos para dar conta da expansão. Algumas vezes ele explicou-nos a estrutura física da casa: haviam dois cômodos grandes e de uso comum, a cozinha, com uma mesa central grande onde havia cadeira para cada um dos moradores, duas geladeiras que abrigavam a comida e os sucos que causavam brigas com as filhas, porque alguns consumiam todo o suco da família. Essa era uma fala recorrente de Chefe, os conflitos pelo consumo do suco.

A sala era o outro cômodo comum, onde havia uma escada que dava para a parte superior onde ficavam os quartos de todos os filhos e netos. O quarto do Chefe e sua esposa era na parte superior da casa. No andar debaixo, ainda havia os quartos menos "nobres". Um deles era ocupado pela "filha de criação", junto com sua filha ("neta de criação" de Chefe).

O filho policial militar, era descrito com orgulho, como herdeiro da responsabilidade pela continuação da família. Homem, organizado nas contas, com emprego público que lhe dava estabilidade, esse filho era a continuidade perfeita da função aglutinadora (WIGGERS, 2006) exercida por Chefe e a garantia de manutenção do espírito da casa. A casa do Chefe é representativa de um padrão de organização de parentesco encontrada na região de Manaus, seja nos municípios da grande Manaus, seja em comunidades rurais dessa região, em que um homem aglutina em uma única habitação todos seus filhos casados com filhos pequenos ${ }^{8}$.

\footnotetext{
7 Ocorre um fluxo de parentes entre Manaus e as cidades do interior do Amazonas, que inclui o compartilhamento de moradias entre membros da mesma família - consanguíneos. Esse fluxo geralmente se dá por motivos de saúde, quando algum familiar precisa de cuidados na capital do estado, ou por problemas de "comportamento", quando algum parente se envolve em "problemas" na sua cidade de origem.

${ }^{8}$ Não podemos afirmar ainda que há um recorte de classe específico para esse padrão, uma vez que tem sido notado, a por meio de outras pesquisas do Azulilás, em famílias de classe média/ alta de Manaus e entorno.
} 
Contudo, uma das filhas casadas de Chefe estava com objetivo de sair da casa e se organizava para ir viver em outra residência com sua família nuclear. Quando os outros filhos casados souberam disso, começaram a tentar fazer o mesmo. $\mathrm{O}$ ideal de Chefe da casa grande abrigando-o a esposa, todos os filhos, filhas, netos, genros e noras começou a ser posto em risco. Nesse contexto, Chefe começou a praticar abusos sexuais contra a "neta de criação" filha da filha da esposa anterior ao casamento com Chefe, e que foi acordado que seria criada como sendo filha dele. Segundo ele, eram masturbações e toques, sem penetração, por um período de tempo que durou cerca de um ano.

O estopim da ameaça de desconfiguração daquela família tal como foi concebida por Chefe ocorreu no momento em que o filho, o policial militar, anunciou que também iria sair da casa. Sob o que considerou uma ameaça do filho, Chefe ao chegar em casa após o trabalho na madrugada, e depois de passar no bar, como era de costume, entrou no quarto ocupado pela filha e pela neta de criação, na época com sete anos de idade, estuprando-a com uma violência brutal. Após cometer a violência, Chefe dorme por um tempo impreciso, e ao acordar, liga para o filho, policial militar, avisando que havia estuprado a "neta de criação" e estava indo à delegacia para "se entregar".

Para compreendermos o contexto da violência sexual cometida por Chefe e os eixos de relação de parentesco, examinemos a genealogia que segue:



$\mathrm{CH}:$ Chefe

eCH: Esposa de Chefe

CHf1: Filha 1 de Chefe CHf2: Filha 2 de Chefe

CHf3: Filha 3 de Chefe CHF: Filho de Chefe
nCH: Neto/a de Chefe eCHf: Filha da esposa de Chefe neCHf: Neta da Filha da Esposa de Chefe $\longrightarrow$ : eixo da violência sexual

X : ruptura no vínculo de parentesco 
A partir da genealogia de Chefe percebemos que a violência sexual ocorreu no eixo de relação de parentesco mais "distante" entre os membros da casa. Mesmo que Chefe tivesse outras netas e outras filhas, não foi contra nenhuma delas, suas consanguíneas, que perpetrou a violência, mas contra a filha da filha de sua esposa, chamada por ele de "neta de criação", mas que não tem com ela relação de consanguinidade.

O filho para impedir que o pai fosse preso acionou todas as irmãs, filhas de Chefe para que contivessem a revolta da mãe da criança violentada. Assim, sob pressão familiar ela demorou dias para denunciar o abuso sexual sofrido por sua filha, entre outras coisas porque ela foi trancada em casa. Porém, ninguém consegue impedir o Chefe de efetivar a denúncia contra si mesmo. No entanto, o que seriam as provas, o exame de corpo delito, a narrativa da criança, foram contidas por um tempo, corroborando para que a denúncia dele ficasse sem comprovação empírica; trabalho exercido principalmente pela esposa de Chefe, convencendo a mãe da criança a não legitimar a denúncia do marido.

Porém, dias depois a "filha de criação" conseguiu sair da casa, levou a criança para os órgãos da rede de proteção e formalizaou o processo contra o autor da violência, mesmo sem o apoio da mãe e dos irmãos. Depois dessa ocorrência dramática, os filhos de Chefe não falaram mais em sair de casa, ao invés disso, se concentraram em torno do pai, a fim de protegê-lo, com discursos relativos à sua perda, possível prisão e "estupro na cadeia”.

Já a "filha de criação" sofre a primeira derrota no processo contra Chefe. Os laudos do IML e do Serviço de Atendimento às Vítimas de Violência Sexual não são equivalentes ${ }^{9}$. Assim, a violência cometida por Chefe é mais uma das caracterizadas como "sem materialidade" e a primeira audiência na justiça é marcada um ano após a denúncia.

O período de audiências é marcado por muita tensão familiar, com muito medo de Chefe seja condenado e preso. Mas a "filha de criação" de Chefe decide não comparecer e abandonar o processo, que acaba sendo arquivado. Pouco depois do período das audiências, filha e neta "de criação" de Chefe, fazem "as pazes" e voltam à casa da família10.

\section{O Caso Rei Salomão}

A história de Rei Salomão é permeada de idas e vindas entre Manaus/AM, Parintins/AM e Santarém/PA. Ele nasceu em Parintins, nas terras do pai, um

\footnotetext{
${ }^{9}$ Há um embate em torno da produção dos laudos de violência sexual no Amazonas. A equipe do SAVVIS - Serviço de Atendimento à Vítima de Violência Sexual -, acusa o IML de não ter equipe técnica e material especializado para o atendimento às vítimas de violência sexual. Além disso, a justiça aceita apenas o laudo do IML como prova de materialidade da violência, sendo o SAVVIS um espaço para acolhimento e primeiros socorros em saúde às vítimas.

${ }^{10}$ Para que uma denúncia de violência sexual seja levada à justiça, ela precisa tramitar em diferentes órgãos. No caso das violências sexuais contra crianças e adolescentes, a denúncia tramita pela Rede de Proteção à criança e ao adolescente. Em algum ponto dessa tramitação, muitas vezes a denúncia para ou é retirada - e as causas são burocráticas, por impedimentos socioeconômicos de as vítimas e a familiares em ir aos órgãos, ou porque a família decidiu não continuar os processos. Nessa saga pelos órgãos de justiça, ocorrem agravamentos como, atendimento de agentes (principalmente da polícia) que não são capacitados para colher depoimentos das vítimas, promovendo revitimizações ou duvidando da palavra das vítimas durante as denúncias; problemas nos laudos que atestam a "materialidade do crime" (ver LOWENKRON, 2012) - uma coisa que se diz bastante nas redes de proteção é que "você precisa pegar o autor da violência no ato", pois isso facilita uma denúncia com provas materiais mais consistentes e caracteriza um flagrante. Essas são dificuldades de primeira ordem, no acesso à proteção e garantia de direitos, que colaboram para que as famílias construam suas próprias alternativas de resolução, que são "mais fáceis", do que o percurso nas instâncias do Estado (ver LOPES LEITÃO, 2016; WIGGERS e LIMA, 2014).
} 
pouco mais afastadas do centro da cidade. Contou-nos que andou um tempo, impreciso, por Santarém, junto com a família, mas retornou à Parintins ainda durante sua infância.

Aos 14 anos de idade, quando estava trabalhando na roça do tio, passou a ser acompanhado no trabalho por uma moça da região, que na época tinha 22 anos de idade. Certo dia, após chegar em casa e contar para o tio sobre a moça, este lhe perguntou "e o que tu fez com ela? Tu não fez nada?", rindo do adolescente. No dia seguinte, o tio lhe entregou uma revista pornográfica e disse "mostra isso aqui pra ela quanto tu chegar lá [na roça]”.

Rei Salomão contou que seguiu o conselho do tio, mostrou a revista ao que a moça reagiu com um “Olha já!” animado, típico do Amazonas. Em suas palavras, foi a partir disso que num "roça daqui, roça dali" teve sua primeira relação sexual. Foi pra casa "radiante", contou ao tio sobre o ocorrido e ambos celebraram sua "primeira vez". Depois de sua primeira relação sexual e vendo a história do Rei Salomão da Bíblia, com muitas mulheres e filhos, o rapazinho decidiu que "queria ser que nem esse Rei Salomão ali”.

A moça com quem Rei Salomão teve sua primeira relação sexual engravidou dele, e diante do caso, houve "rebuliço" na comunidade"1. Rei Salomão estava disposto a casar e assumir a criança, mas a família da moça não apoiou a união, porque ele era muito jovem. A família do rapaz acionou a justiça para resolver o impasse, mas um juiz interpretou que, por ser menor de idade Rei Salomão não precisaria casar. Ele pediu para casar com a moça e chegaram a ficar juntos alguns meses após o nascimento da criança, mas logo ela o deixou, mudando-se para outra cidade.

Anos mais tarde, depois de vários romances, ele se casou formalmente e continuou morando na casa do pai. Essa casa tinha o formato da casa do Chefe, com o pai sendo o sujeito aglutinador da família, e os irmãos e cônjuges morando junto. Com sua primeira esposa, Rei Salomão teve três filhos, mas após o terceiro filho, a mulher, a quem sempre chama de "a mãe dos meus filhos", deixou a casa do sogro, e os filhos com o pai.

Após a partida da "mãe de seus filhos", Rei Salomão também decide ir embora, levando consigo apenas dois dos três filhos, para cuidar de uma terra ${ }^{12}$, em alguma região imprecisa, entre Parintins e Manaus.

Ao chegar na terra, Rei Salomão descobriu que se tratava de uma área ilegal, permeada de conflitos entre grileiros. O dono das terras lhe deu uma casa velha, feita de madeira e com telhas de zinco, para morar com os dois filhos. Nesse período, Rei Salomão afirma que passou "fome e sufoco", que "quase morreu com as duas crianças", não recebendo os valores prometidos como pagamento por seu trabalho, e sendo, muitas vezes, ameaçado de morte. Em uma noite, após passarem o dia trancados na casa dada pelo grileiro, depois de haverem ocorrido assassinatos entre os capangas dos homens que disputavam a terra, Rei Salomão recebeu ajuda de um dos homens da casa do "proprietário", para fugir com os meninos. Eles saíram soturnamente, na madrugada, e Rei Salomão conseguiu retornar para a casa do pai, em Parintins.

Depois desse retorno, passou a viver com o pai durante alguns anos, de vez em quando, "arrumando uma mulher, fazendo um filho aqui, outro ali". Ele falava detalhadamente de apenas de três filhos, do seu casamento "oficial", que fazia questão de manter perto, enquanto morava na casa de seu pai. Mas, Rei Salomão

${ }^{11}$ Esse "rebuliço" é comum até hoje nas comunidades quando uma menina ou moça engravida. Pais, parentes e vizinhos opinam sobre o destino do casal e da criança.

12 Um acordo informal para cuidar de uma propriedade rural. Uma atividade próxima do que faria um "caseiro", mas diferente por conta das formas de organização dessa propriedade e da relação com a terra. 
conta pelo menos 17 filhos ao todo "espalhados pelo mundo", de relações com cerca de 22 mulheres.

Em certa altura, deixando os filhos com o pai, em Parintins, veio morar em Manaus. Chegou sem emprego, mas conseguiu um trabalho no porto, logo depois alugou uma casa e foi organizando a vida. Num dos dias de trabalho no porto de Manaus, conheceu uma mulher grávida, e lhe chamou pra morar consigo, comprometendo-se em assumir a criança que viria a nascer, como seu filho. Ela aceitou e os dois passaram a morar juntos, sob o acordo de que ela deveria "cuidar dele como homem", e ele deveria mantê-la:

\begin{abstract}
Ela cuidava da casa, deixava tudo arrumado, fazia minha comida, mas quando chegava na hora de comparecer ela escapava. Todo dia eu chegava e era a mesma história, a comida ótima, ela botava no prato, café da manhã sempre bem feito, tudo bonitinho, mas e cuidar de mim com homem? Nada. Até que um dia eu cansei disso e falei pra ela 'olha você tem que comparecer. Que negócio é esse de não me querer? Já faz seis mês isso! Seis mês! Eu lhe dei teto, vou assumir sua criança, mas você tem que...né, comparecer. Não tá certo isso não!"'. Aí ela disse que não queria mesmo assim. E eu disse 'pois eu vou fazer', e ela atrevida ainda falou 'se você fizer eu vou embora'. Aí eu duvidei e fui pra cima dela e fiz. Quando acordei, tinha só o café da manhã na mesa. Ela foi embora mesmo. Nunca mais apareceu.
\end{abstract}

No tempo seguinte, Rei Salomão contava que ficou "sem mulher", até que encontrou, também no porto, uma mulher com quem já havia tentado namorar na juventude, moradora de Manaus, mas que estava vindo de Parintins: "Agora vai, eu vou conseguir conquistar ela”. Ela era evangélica, por isso, ele acabou entrando para a igreja também e mais tarde, com sua insistência, casaram.

Ela já tinha uma casa, e Rei Salomão, que antes morava de aluguel, e já havia "perdido" um terreno, num conflito em uma ocupação em Manaus, assim, foi morar com a nova esposa.

Ele continuou trabalhando no porto de Manaus até conseguir se aposentar. Ela era lavadeira e também fazia faxina. Eles tentaram ter filhos três vezes, mas em todas ela abortou. Ela já tinha um filho adulto, e assim como ele, era uma mulher de meia idade na época.

O filho da esposa de Rei Salomão tinha um filho, um menino de 6 anos, com quem frequentava cotidianamente a casa da mãe. Rei Salomão dizia não gostar do menino, pois era muito traquino. Certo dia, a criança foi deixada com a avó, esposa do Rei Salomão. Enquanto isso, ela recebeu um telefonema para ir fazer uma faxina, e deixou o neto sob os cuidados de Rei Salomão, que abusou sexualmente da criança, nessa ocasião.

A mulher de Rei Salomão, após a denúncia, defendeu o marido. Seu filho passou a não frequentar mais a casa da mãe.

A seguir, a genealogia de Rei Salomão, para compreensão dos eixos de relação envolvidos em sua trajetória até o abuso sexual: 


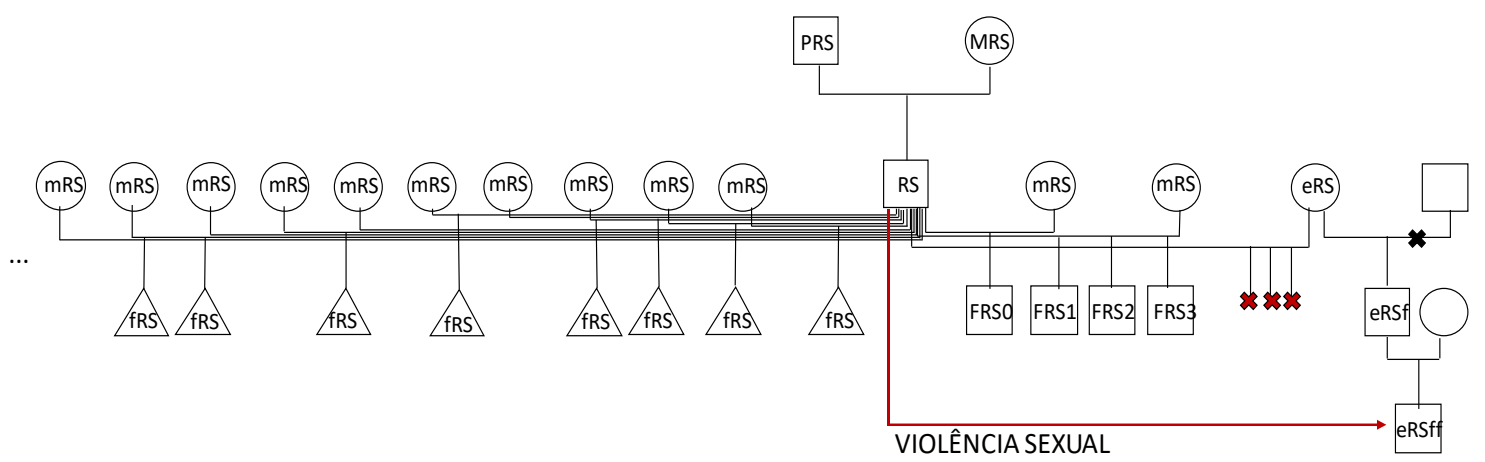

RS: Rei Salomão PRS: Pai de Rei Salomão MRS: Mãe de Rei Salomão eRS: Esposa de Rei Salomão RSO: Filho de Rei Salomão RS1: Filho 1 de Rei Salomão
RS2: Filho 2 de Rei Salomão RS3: Filho 3 de Rei Salomão fRS: Filhx de Rei Salomão eRSf: Filho da esposa de Rei Salomão eCHff: Filho do Filho da Esposa de Rei Salomão mRS: mulher de Rei Salomão

Rei Salomão nos contava que sempre acontecia alguma emergência familiar e esposa abortava. Da última vez, foi por causa de um evento, envolvendo o filho mais novo de Rei Salomão:

\begin{abstract}
Ele veio morar um tempo comigo em Manaus. Era um menino novo. Menino bom. Não devia ter vindo, mas ele vivia pedindo pra vir e eu deixei, porque o do meio veio antes e casou. Aí ele quis vir também. Ficou morando com a gente. Um dia ele foi numa festa, tava a fim de uma mocinha e foi atrás. Mas a menina tinha namorado e o cara era um bandidão desses que arrumou confusão com ele na festa e meu filho decidiu vir pra casa. O problema é que o cara seguiu ele e quando foi perto de casa, o bandido deu uma facada no bucho do meu filho que rasgou. Aí ele conseguiu puxar o celular pra me ligar. Quando ele falou comigo eu fui atrás com o carro do meu cunhado. Mas o menino era forte, era brabo. Foi andando pra casa. Aí quando ele chegou lá, minha mulher abriu a porta e viu as tripa dele tudo pra fora. Aí ela não aguentou e abortou. Depois disso ela não engravidou mais. E ele virou um menino mau. Ele era um menino bom, mas depois disso parece que deu alguma coisa nele. Se meteu com tudo que não prestava. Não sei nem o que é dele. Sumiu. Tavam procurando ele pra prender, mas ele sumiu. Tomara que não esteja morto por aí.
\end{abstract}

Não sabemos ao certo até onde, de fato, Rei Salomão realmente desconhecia o paradeiro do filho. Geralmente as famílias de camadas populares que residem em Manaus, têm alguma rede de parentes no interior. Rei Salomão relata essas redes, esses intercursos por diferentes cidades entre Parintins e Manaus, circuito que é compartilhado também por seus filhos.

Dos outros dois filhos, dizia confiar mais no filho mais velho, que morava na casa de seu pai, em Parintins. Já o filho do meio, em certo momento, durante a participação de Rei Salomão no Grupo de Autores, começou a "arranjar problemas", aparentando que estava "de caso com outra mulher". Algum tempo depois, Rei Salomão nos contou que o filho foi posto pra fora de casa pela esposa, e está abrigado em sua casa. Além disso esse filho começou a ser descrito como "alcoólatra".

Acordei, fui na padaria pra comprar pão, tava ele lá na frente de casa, estirado no meio da calçada. Uma vergonha. Aí eu pensei 'eu vou fotografar pra mostrar pra ele'. Entrei, peguei a câmera e tirei um monte de foto dele naquela situação. Quando ele acordou peguei a câmera e mostrei pra ele, "olha aqui tua situação rapaz! Tu acha isso bonito?! Vai criar vergonha, se arrumar com Deus!” 
Mais tarde, ainda no tempo do "Grupo de Autores", Rei Salomão contou que o filho do meio já estava "melhorando do vício", que conseguiu um emprego e estava frequentando a igreja. Nesse ínterim, o pai de Rei Salomão foi trazido por ele à Manaus, para realizar alguns exames. Por se negar a fazer uma depilação no púbis para realizar os exames, o pai de Rei Salomão perdeu todas as consultas marcadas e também passou a morar em sua casa, em Manaus, até a realização do próximo exame.

Assim, é possível notar que, após o afastamento do filho da esposa, através do abuso sexual contra o filho do filho da esposa, Rei Salomão, aglutina seu pai e seus filhos para morarem consigo na casa de Manaus.

\section{A diferença entre Sexo e Casamento: incesto e "abuso sexual intrafamiliar"}

Fox (1986) aponta que há uma confusão comum nos estudos de parentesco sobre a diferença entre "sexo" e "casamento", principalmente no que concerne a classificação do incesto. O autor indica que é necessário distinguir incesto e exogamia: "onde o incesto diz respeito às relações sexuais e a exogamia diz respeito às relações conjugais.” (FOX, 1986). Sexo e casamento são pensados como intrínsecos, mas não são a mesma coisa. O casamento pressupõe que hajam relações sexuais entre o casal, portanto, as relações sexuais tabu, ou incestuosas, classificam de antemão aqueles sujeitos com quem não se pode casar.

A discussão sobre abuso sexual intrafamiliar, além de versar sobre um crime sexual, tipificado no código penal brasileiro através da Lei 13.718/2018, também passa por um debate moral sobre sexo e casamento. Até meados de 2010 o termo mais utilizado para o abuso sexual cometido em família era "abuso sexual incestuoso", tendo sido amplamente discutido nos estudos de gênero e violência (ver SAFIOTTI, 2001, 2004)

O "abuso sexual incestuoso" equivale ao "abuso sexual intrafamiliar", e classifica violações sexuais entre parentes. Na legislação brasileira existem dois caminhos possíveis para a proibição do sexo entre parentes. Um, a já comentada lei de crimes sexuais, que tipificará no código penal, as violências sexuais contra crianças e adolescentes. Essa lei pressupõe a incapacidade de consentimento de crianças e adolescentes, menores de 14 anos, para qualquer relação sexual (LOWENKRON, 2012). Outro percurso se dá no código civil, Lei 10.406/2002, por meio das regras de casamento e filiação. Nenhuma dessas leis fará qualquer classificação sobre "incesto", mas indiretamente, ambas dispõem de regras que interditam relações sexuais e casamento.

Há na formação da categoria "abuso sexual intrafamiliar", um duplo interdito, primeiro, do sexo entre um adulto e criança, sem capacidade de consentimento, segundo, do sexo entre parentes. Propomos, para efeito de análise dos casos de abuso sexual intrafamiliar aqui demonstrados, uma aproximação à categoria "incesto", considerando que ambas, classificam interditos morais sobre sexo, casamento e família.

Na obra de Lévi-Strauss, o incesto aparece como base das regras prescritivas de casamento - por meio do casamento se faz a aliança entre dois homens, entre dois grupos. Contudo, há um equívoco em torno no incesto, apontada discretamente pelo próprio Lévi-Strauss, fora das Estruturas Elementares, que está no modo de como os sujeitos, em suas descrições, assimilam sexo a casamento.

Outro fator importante sobre o incesto, é o alarido que se faz (ou não) em torno dele. Vernier (1996), aponta que o incesto não é notado como um problema 
simplesmente pela tensão entre consanguinidades, mas a partir do sentimento de ofensa, de uma pessoa contra uma rede de parentes. Esse sentimento de ofensa precisa ser reclamado publicamente, por um conjunto de parentes, que como linhagem, defendem a pessoa ofendida. Para Vernier (2008), o incesto e suas consequências são desdobramentos de atos políticos, no sentido que Bourdieu (1998) atribuiu à ação política como possibilidade de alteração estrutural. Um ato incestuoso só o será, se houver uma linhagem de parentes para reclamá-lo em nome da pessoa ofendida.

Essa interpretação em muito se aproxima das realidades aqui apresentadas como típicas dos casos de "abuso sexual intrafamiliar", verificados no Amazonas. Há uma recorrente tensão familiar na disputa por quem deve ser o sujeito protegido (agressor ou vítima). Repetidamente, essa tensão provoca a aglutinação dos consanguíneos (do agressor) e fortalecimento do vínculo de afinidade entre o casal 13

\section{Afinidade, consanguinidade e cognação}

O conflito familiar, nos casos de Chefe e Rei Salomão têm como clímax o abuso sexual intrafamiliar, mas antecedem o abuso sexual em si. O "abuso sexual intrafamiliar", ou incestuoso, ocorre nesse contexto, renegociando os conflitos familiares onde é acionado. Logo, parece fundamental olhar os vínculos de parentesco, buscando pensar o que aproxima e distancia parentes, e como esses os eixos de parentesco produzem status diferentes nesses casos.

Primeiro, cabe retomar a discussão de Lévi-Strauss sobre o átomo de parentesco. Para Lévi-Strauss a origem da família e do estado de sociedade está colocada na produção da exogamia (necessidade de casa fora do grupo) a partir da proibição do incesto (ou prescrição de casamento).

Discordando de Radcliffe-Brown e dos autores da escola estrutural-funcionalista (Meyer Fortes, E. E. Evans-Pritchard, entre outros), Lévi-Strauss propõe que a proibição do incesto, que origina a sociedade, como regra ao mesmo tempo natural e social, se dá porque os diferentes grupos humanos precisam estabelecer vínculos entre si, evitando a guerra. Para isso, homens de classes diferentes (ver Durkheim e Mauss; Lévi-Strauss) devem trocar mulheres de seus grupos, por meio de casamento. Assim, funda-se o átomo de parentesco, baseado na relação entre cunhados, que gera a família.

A ideia central desse argumento é de que a sociedade só se forma por meio da conciliação entre dois homens através da troca de mulheres. Lévi-Strauss (1989) afirma que um fato universal nas sociedades humanas é "que para que um homem tenha uma esposa, é preciso que ela lhe seja direta ou indiretamente cedida por outro homem, que nos casos mais simples está na posição de pai ou irmão em relação a ela”.

Considerando as diversas críticas a esse modelo conceitual da "troca de mulheres”/exogamia (ver RUBIN, 1989; BUTLER, 2003), é importante frisar que esse princípio, e suas variações, vigorará no sistema de parentesco das "terras baixas da América do Sul", subdividido em duas grandes regiões, a do Brasil Central, classificada a partir de "Estruturas Elementares do Parentesco" de Lévi-

${ }^{13}$ Há elementos morais generalizados sobre a validade da palavra da vítima, principalmente quando se trata da palavra de uma criança, ou quando os interesses nas relações familiares já estão em disputa (principalmente em casos de divórcio) - entre o homem acusado pela violência sexual e a mulher responsável pelos cuidados da criança. A cenas de violência sexual intrafamiliar, estão situadas em contextos de conflito familiar, que envolvem múltiplas agressões entre sujeitos que convivem no espaço doméstico (ver GREGORI, 1993; GROSSI, 2008; WIGGERS, 2000). Os conflitos são marcados por diferenças e disputas nas relações de poder, onde o uso da violência tende a aglutinar de um mesmo lado (em oposição ao agressor), mulheres e crianças (ver ORTNER, 1979; MARCHI, 2011; LIMA, 2018). 
Strauss como de ordem "crow-omaha”, e a região da Amazônia, que tende a ser classificada como "dravidiana” (VIVEIROS DE CASTRO, 2002).

Dravidianato é o termo designado por Louis Dumont para analisar o sistema de parentesco da Índia do Sul, que opõe consanguinidade e afinidade, considerando a consanguinidade pela linha paterna e a afinidade pelas relações matrilineares. Eduardo Viveiros de Castro (2002), ao refletir sobre o "problema da afinidade na Amazônia" levanta inicialmente algumas hipóteses sobre o tipo de sistema de parentesco, dentre os esquemas existentes, que mais se aproxima do caso Amazônico, levando em conta a diferenciação, entre consanguíneos e afins, mas é específico em relação ao caso indiano, por conta da fluidez dessa oposição. Considerando todas as críticas sobre a complexidade de pensar um "dravidianato amazônico", Viveiros de Castro incorre na necessidade de enriquecer o paradigma dravidiano e tecer algumas generalidades, pensando, a partir do dravidianato, o problema amazônico.

Uma categoria importante no caso amazônico é a de "cognação", que media a fluidez entre consanguíneos e afins. A cognação configura as relações de sangue da linha materna, fazendo com que todo cognato seja um afim classificatório, e ao mesmo tempo, um consanguíneo potencial. A consanguinidade, ou laços de sangue - que permeiam a herança -, será sempre, no caso do dravidianato, a categoria que perpassa o parentesco pela via paterna. A cognação é a categoria que designa laços de sangue pela via materna. Enquanto, afinidade é a categoria que, tomando a consanguinidade como perspectiva, designa tanto os cognatos, quanto consanguíneos muito afastados (VIVEIROS DE CASTRO, 2002). Os parentes pela linha de um homem, são os consanguíneos, enquanto os parentes pela linha de uma mulher, são cognatos entre si, e afins potenciais.

Segundo Viveiros de Castro (2002) existem alguns problemas da afinidade na Amazônia. $\mathrm{O}$ primeiro seria a ausência de termos distintos para a afinidade. $\mathrm{O}$ segundo, a diversidade de termos que operam como um continuum entre afinidade e consanguinidade. $\mathrm{O}$ terceiro, a ambiguidade da afinidade na Amazônia. $\mathrm{O}$ autor afirma que existe uma diferença básica em torno da configuração de afins e consanguíneos. Os afins são parentes distantes e classificatórios (com quem se pode casar), os consanguíneos são os parentes próximos (onde se aplica a proibição do incesto). Essa classificação é chamada de "endogamia prescritiva" por Riviére entre os Piaroa das Guianas e preconiza que os afins efetivos têm que estar ligados por cognação (consanguinidade materna). Além disso, dada a distância de vínculo na rede de parentesco, um afim cognato próximo do ego pode ser classificado como uma espécie de "subconsanguíneo". Do mesmo modo, um consanguíneo muito distante pode se tornar um afim potencial. Viveiros de Castro (2002) conclui que "afinidade e consanguinidade são duas classes que se definem por negação. De modo que um afim sempre será igual à um não consanguíneo, ou ao contrário, um consanguíneo sempre será um não-afim”.

Ainda que o contexto do dravidianato amazônico seja específico para os sistemas de parentesco no Noroeste Amazônico e Guianas, a pendulação entre afinidade e consaguinidade, por meio dos parentes por cognação, pode nos ajudar, como um esquema sociológico que possibilite refletir sobre os casos de "abuso sexual intrafamiliar”, aqui analisados. Nesses casos, há tendência de um parente por afinidade, ser incluído no grupo de consanguíneos a partir da troca de fluidos.

A partir do conjunto de nossas pesquisas com famílias de grupos populares no Amazonas, temos notado a recorrência em torno do modo de como as mulheres tecem família, importante para pensar formas de organização familiar e conflito específicos da região. 
Nesses casos a primeira gravidez ocorre, geralmente, na adolescência, provocando a saída da casa dos parentes, ou a criação de um núcleo familiar com o pai da criança gestada. Isso configura um primeiro casamento, que tende a ser dissolvido pouco após o nascimento da criança. Tanto os casos de Chefe e Rei Salomão, quanto observações preliminares de outros contextos em grupos populares no Amazonas, tem nos mostrado que a mulher sai da casa de origem, ou da primeira casa, e associa-se, no segundo casamento, para a criação de uma nova casa, com o segundo (ou mais) parceiro, após o primeiro casamento.

A mulher pode ou não levar o primeiro filho para o segundo casamento. Essa variável ainda não teve uma delimitação precisa nas nossas pesquisas, mas já podemos apontar que o filho do primeiro casamento tende a circular por mais parentes, pois representa um risco ao novo casamento da mulher. Pode ocorrer de uma mulher circular fora da casa, mas ter um "marido de referência", que será o pai de todos os seus filhos.

Os casos em que o primeiro filho da mulher é incluído (por ela) na nova família, têm recorrência de "abuso sexual intrafamiliar" no eixo "padrasto-enteado/a”.

Um consanguíneo de outro homem representa o cerne do conflito intrafamiliar, com duas variáveis que os casos de Chefe e Rei Salomão, ilustram bem: (1) um casamento sem filhos, fragiliza o vínculo entre afins; (2) consanguíneos apenas da linha feminina, em convívio com consanguíneos do casal, arriscam a fragmentação da família.

O abuso sexual intrafamiliar, ou incestuoso, radicaliza as tensões entre afinidade e consanguinidade; os agressores atuam com propósito de homogeneizar todos os sujeitos da família sob uma mesma classificação, dissolvendo a pendulação dos "mais ou menos consanguíneos", ou cognatos.

\section{A função da troca de fluidos em família}

Uma conferência dada em 2003 por Françoise Herítier, no Musee d'el Homme, em homenagem a Marcel Mauss, pode auxiliar na compreensão da tensão entre consanguinidade e afinidade, sobretudo, na circulação dos fluidos corporais como compositores do parentesco.

Discordando de de Lévi-Strauss, para quem as regras sociais que baseavam a mudança do estado de natureza para o estado de cultura estavam ancoradas no pensamento, Heritiér (1996) argumenta que a âncora do social sempre será o corpo, a natureza, a diferença biológica. Para a autora, a evitação da guerra, a proibição do incesto, a exogamia e a divisão sexual das tarefas, bases da vida social, serão construídas primeiro, a partir da valência diferencial dos sexos.

Nesse sentido, para Heritiér $(1996,2003)$, uma pessoa é feita a partir de corpos e substâncias diferentes (masculino e feminino). Contudo, existem formas distintas de transmissão dos fluidos, e, portanto, de fabricação dos laços de parentesco. Usando o exemplo do grupo étnico Samo, do Brukina Fasso, Heritiér afirma que naquele contexto uma criança herdava esqueleto e sangue de sua mãe, enquanto de seu pai, herdava a carne. No início da vida, a criança produziria sangue a partir da medula, herdada da mãe, que continha também sangue de seu avô materno. O sangue paterno estava disponível na carne e era somado ao sangue produzido a partir das substâncias herdadas da mãe. Assim, o sangue paterno sempre representava um vínculo de primeira via, enquanto o vínculo materno era herdado de relações com maior profundidade geracional. 
Heritiér tratou muito bem da importância dos vínculos de parentesco que passam pelos fluidos corporais - reforçando a presença dos fluidos como mobilizadores do parentesco na formação da pessoa. O sêmen, o leite, o sangue e a medula são os fluidos que fazem a vida, em maior ou menor profundidade de vínculos (por geração). Ao apresentar considerações sobre o caso Samoa, Heritiér (2003) argumenta que as substâncias maternas eram as de maior profundidade na segunda geração, uma vez que a medula é feita do sangue do avô, que gera o sangue de todo o corpo, após o nascimento. As substâncias paternas eram sempre as de primeira via, fazendo o sangue e a vida da nova pessoa, a través do esperma, gerador do primeiro sangue e da placenta. A autora reforça algumas das ideias de Lévi-Strauss, principalmente em torno da formação e da importância dessa nova pessoa, esse ser que aglutina fluidos de duas famílias/linhagens, como compositor efetivo do casamento.

Suspendendo o contexto do exemplo usado por Heritiér em sua elaboração teórica sobre a importância dos fluidos como compósitos da pessoa e do parentesco, podemos seguir seus rastros, para refletir sobre as mobilizações em torno das relações de parentesco, nos casos de abuso sexual intrafamiliar, ou incestuoso, apresentados anteriormente.

No caso de Rei Salomão, vimos que ocorrem tensões em meio a diversas tentativas frustradas de ele ter filhos com sua última esposa. Além disso, percebemos a ênfase que ele elaborava em seus relatos sobre a importância de ter filhos para classificar casamentos. Mais do que "ter muitas mulheres", era importante para ter filhos com essas mulheres. Coisa que não ocorreu com sua esposa. Nesse sentido, voltamos à lógica sobre quais são os vínculos fortes/fracos nessas relações familiares. O abuso sexual intrafamiliar cometido por Rei Salomão contra o neto de sua esposa, num primeiro momento, promove o afastamento entre a esposa e seus consanguíneos. Mas, em segundo plano, constrói por meio dos fluidos que circulam nesse abuso sexual incestuoso, uma pessoa virtual que efetiva seu próprio casamento. Esse sexo, além de afetar diretamente o neto da esposa de Rei Salomão, concilia, indiretamente, a consanguinidade necessária para afirmar o valor de seu casamento.

No caso de Chefe a tensão estava posta na ameaça de fragmentação da família, com a saída dos seus filhos de sua casa. Chefe comete abuso sexual intrafamiliar, ou incestuoso, com sua "neta de criação". Essa forma de nomear o grau de parentesco com a vítima, é continuamente reelaborada por Chefe em sua narrativa. Apenas quando ele tem o caso arquivado na justiça, porque a representação legal da vítima (mãe da criança) decide não ir às audiências, Chefe exprime com alívio que houve perdão entre os membros da família, que suas, agora "neta" e "filha", retornaram ao convívio da casa. Ao mesmo tempo, Chefe passa a mencionar atos familiares de reconciliação e aglutinamento em torno de si, tanto por meio de uma vigilância dos filhos para com a relação entre Chefe e as crianças da casa, quanto pela ausência de novas tentativas de fragmentação da família: ninguém mais fala em sair de casa. Nesse caso, os fluidos atuaram elaborando uma equivalência de status entre todos os membros da casa, fazendo-os efetivamente filhos e netos de Chefe.

A discussão de Lévi-Strauss (1989) sobre a oposição entre laços de parentesco positivos e laços de parentesco negativos ajuda a visualizar as reconfigurações provocadas pelo abuso sexual intrafamiliar, ou incestuoso. Refletindo sobre o átomo de parentesco, Lévi-Strauss argumenta que a proposta feita nas "Estruturas Elementares do Parentesco" não visava pensar as regras de prescrição do ca- 
samento como rígidas, mas considerando os afetos construídos nos eixos de oposição à prescrição. Por exemplo, se a regra prescreve o casamento entre primos cruzados e matrifocalidade, o irmão da mãe estabelece com o ego uma relação de prescrição, que pode ser permeada ou não de afeto. $O$ vínculo paterno, pode também disputar o valor dessa relação por meio de outras trocas, outros afetos, mesmo sem o peso da regra de moradia e casamento. Há, portanto dois eixos, opostos, em disputa, um negativo e outro positivo, que podemos verificar nas duas genealogias a seguir:

Figura 3-Genealogia de Chefe

CH: Chefe eCH: Esposa de Chefe CHf1: Filha 1 de Chefe CHf2: Filha 2 de Chefe CHf3: Filha 3 de Chefe CHF: Filho de Chefe
nCH: Neto/a de Chefe eCHf: Filha da esposa de Chefe neCHf: Neta da Filha da Esposa de Chefe $\longrightarrow$ : eixo da violência sexual

$\mathbf{X}$ : ruptura no vínculo de parentesco

Figura 4 - Genealogia de Rei Salomão

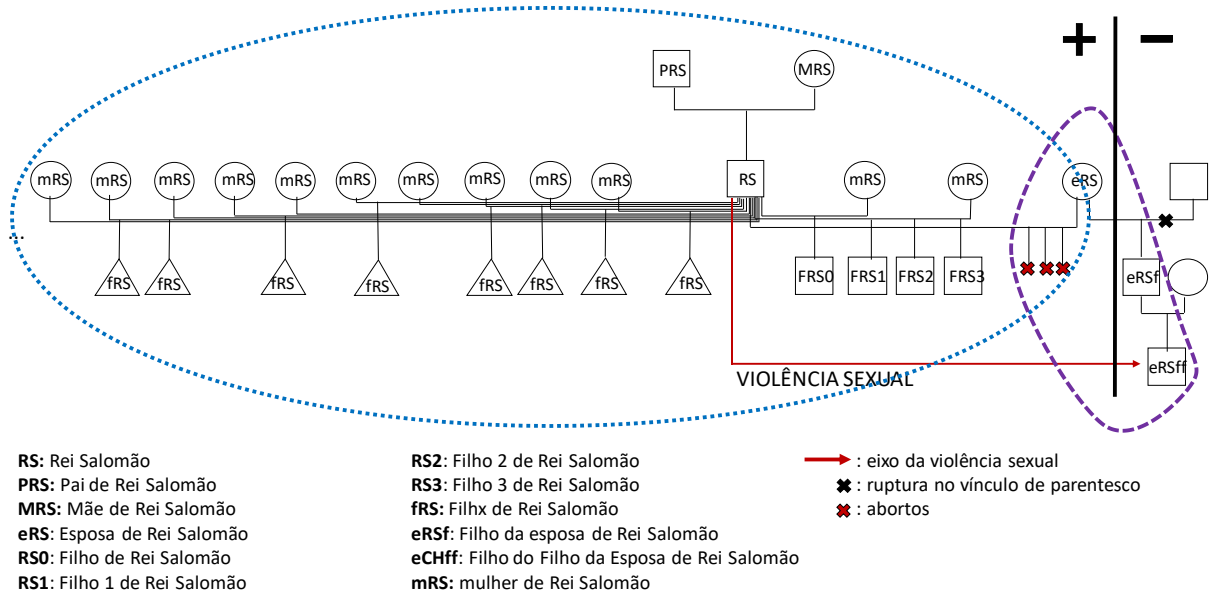


Ao polarizarmos as relações das genealogias, vemos os eixos de tensão, e como cada lado se posiciona em prol de seus interesses. A seta que aponta o eixo de violência sexual, passa a atravessar polos opostos, indicando a intervenção (a violência sexual) de um lado sobre outro.

Essa intervenção, pode modificar o ponto da polarização. No caso de Rei Salomão, a polarização permanece estática após a violência contra o filho do filho da esposa, pois gera a ruptura nos vínculos de consanguinidade da esposa e fortalece o vínculo oposto, entre afins.

No caso de Chefe, após a violência nota-se a tensão dos consanguíneos em relação aos afins, inclusive no processo de constrangimento das filhas de Chefe sobre a filha da esposa do ego, para que ela não consiga realizar a denúncia a tempo ${ }^{14}$. Contudo, no caso de Chefe, após o esgotamento do conflito familiar, e retorno das afins à casa, há um deslocamento no eixo de polarização, e englobamento das afins à consanguinidade, como vemos na genealogia a seguir:

Figura 5 - Genealogia de Chefe

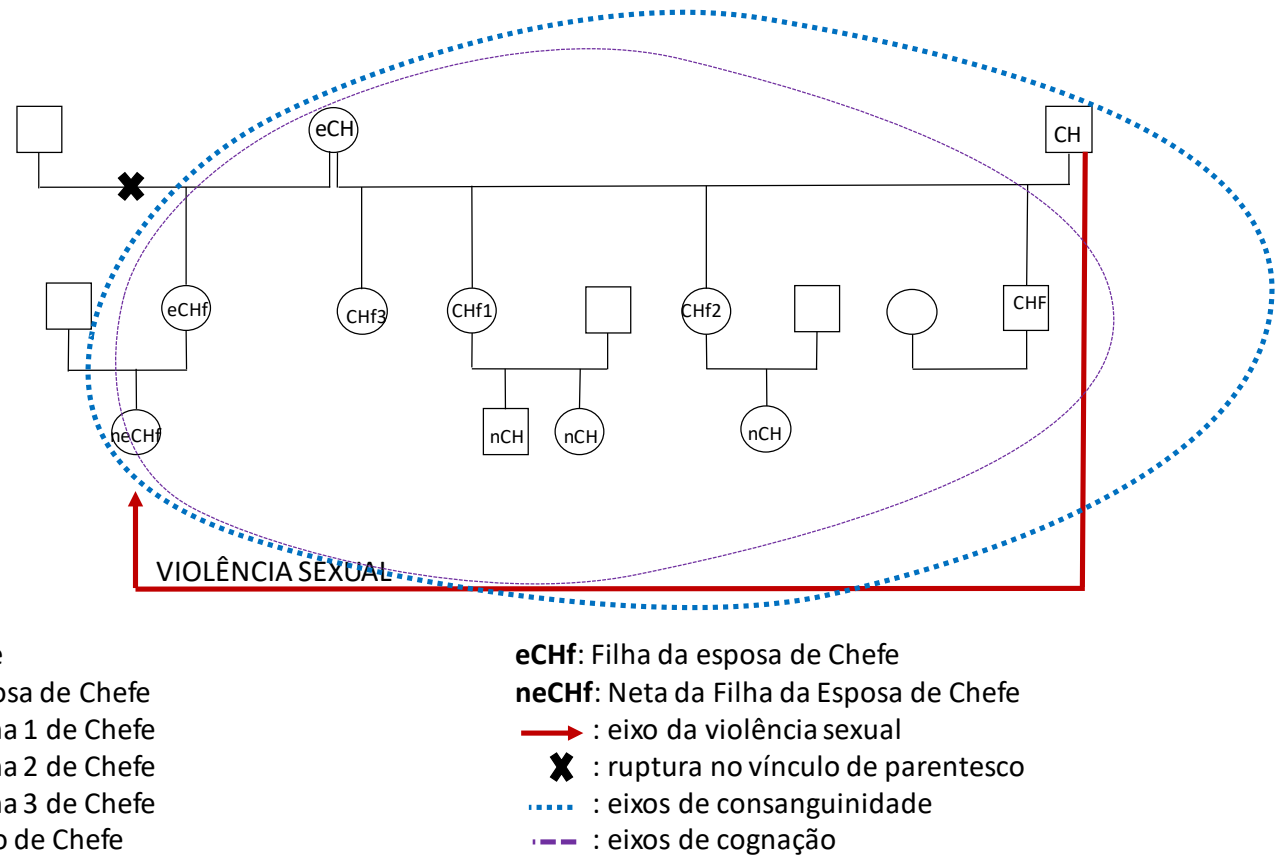

CH: Chefe

eCH: Esposa de Chefe

CHf1: Filha 1 de Chefe

CHf2: Filha 2 de Chefe

CHf3: Filha 3 de Chefe

CHF: Filho de Chefe

nCH: Neto/a de Chefe
eCHf: Filha da esposa de Chefe neCHf: Neta da Filha da Esposa de Chefe

- : eixos de cognação

lizam nosso desejo por justiça e punição dos agressores. Contudo, não é isso que ocorre na maioria das relações familiares em contexto de abuso sexual.

Pode-se imaginar, como talvez creia a maioria das pessoas, que agressores sexuais de crianças e adolescentes, são todos sujeitos com patologias psiquiátricas - pedófilos - imagem abjeta que elaboramos acerca desses crimes. Mas, como

${ }^{14}$ Algo semelhante ocorre num exemplo apontado por Lévi-Strauss (1989) sobre as irmãs terem tendência a uma relação negativa, enquanto a relação entre marido e mulher, tende a ser positiva. 
apontam os dados do Ministério da Saúde e Ministério da Mulher, Família e Direitos Humanos, são pais, avôs, tios, homens comuns, com diferentes status sociais, e sem qualquer indício de parafilia, os autores desses crimes. Como já mencionamos anteriormente, os casos de "abuso sexual intrafamiliar", mesmo com densa subnotificação, correspondem a $80 \%$ dos casos totais de violência sexual no Brasil e no Amazonas.

Apesar de os estudos clássicos de parentesco não terem uma preocupação com a violência sexual, é de interesse dos estudos de parentesco a compreensão de sentidos e padrões de organização familiar. Como argumenta Adam Kuper (2018), ao refletir sobre "o que ainda pode ser dito na Antropologia sobre o parentesco", o parentesco não é uma coisa em si:

Não se trata apenas do formalismo teórico, mas de refletir o que deve ser levado em consideração para explicar um contexto: "Bourdieu invocou as escolhas estratégicas e laços emocionais que precisavam ser levados em consideração, para explicar o casamento com primos paternos entre os Kabyle, bem como os casamentos móveis ascendentes que foram incentivados em sua própria aldeia familiar no Béarn. (KUPER, 2018, tradução nossa)

Fizemos aqui o esforço de aproximar "abuso sexual intrafamiliar" e "incesto" como categorias sociologicamente equivalentes, no intuito de apontar que, mesmo repulsivos, os atos de violência sexual em família, ressaltam e configuram padrões de organização familiar no Amazonas.

Recebido em 31 de janeiro de 2020. Aprovado em 8 de agosto de 2020.

Referências

BOURDIEU, Pierre. Contrafogos: táticas para enfrentar a invasão neoliberal. Jorge Zahar Editor. Rio de Janeiro, 1998.

BUTLER, Judith. O parentesco é sempre tido como heterossexual? Cadernos Pagu, 21 (1), 2003.

FOX, Robin. Parentesco e Casamento - uma perspectiva antropológica. Ed. Vega, 1986.

GREGORI, Maria Filomena. Cenas e Queixas: um estudo sobre mulheres, relações violentas e a prática feminista. Rio de Janeiro: Paz e Terra; São Paulo: ANPOCS, 1993.

GROSSI, Miriam P. "Violência, Gênero e sofrimento”. In: RIFIOTTIS, Teophilos; HYRA, Tiago (org.). Educação em Direitos Humanos: discursos críticos e temas contemporâneos. Florianópolis: EdUFSC, 2008.

HERITIER, Françoise. Une anthropologie symbolique du corps. Journal des Africanistes, 2003: 73-2. 
HERITIER, Françoise. Masculino, Feminino - o pensamento da diferença. Ed. Piaget, 1996

KUPER, Adam. We need to talk about kinship. Anthropology of this Century, 23, 2018.

LIMA, Natã Souza. "Masculinidades e Cuidado: um relato antropológico sobre o Grupo de Autores em Manaus". In: WIGGERS Raquel; LIMA, Natã Souza (orgs.). Abuso e exploração sexual: notas para um debate multidisciplinar. Manaus: Valer, 2015 .

LIMA, Natã Souza. Entre mundos de sentido: Violência Sexual, Família E Parentesco a partir do Grupo de Autores em Manaus/AM. Dissertação de Mestrado em Antropologia Social, PPGAS-UFAM, 2018.

LEITÃO, Consuelena Lopes. Limites e Possibilidades: uma tentativa de aproximação antropológica com a realidade de adolescentes em situação de exploração sexual na Cidade de Manaus. Tese de Doutorado em Antropologia Social, PPGAS-UFAM, 2016.

LÉVI-STRAUSS, Claude. Antropologia Estrutural. São Paulo: CosacNaify, 2008. LÉVI-STRAUSS, Claude. Antropologia Estrutural Dois. Rio de Janeiro: Tempo Brasileiro, 1989.

LÉVI-STRAUSS, Claude. As estruturas elementares do parentesco. Petrópolis: Vozes, 1982.

LÉVI-STRAUSS, Claude. Mitológicas I - O cru e o cozido. Rio de Janeiro: CosacNaify, 2004.

LOWENKRON, Laura. O Monstro Contemporâneo. Tese de Doutorado em Antropologia Social, PPGAS-Museu Nacional, 2012.

MARCHI, Rita de Cássia. Gênero, infância e relações de poder: interrogações epistemológicas. Cadernos Pagu, 37 (1): 387-406, 2011.

MINISTÉRIO DA FAMÍLIA, MULHER E DIREITOS HUMANOS (Brasil). Disque Direitos Humanos - Relatório. Brasília: Ministério da Família, Mulher e Direitos Humanos, 2020.

MINISTÉRIO DA SAÚDE (Brasil). Análise epidemiológica da violência sexual contra crianças e adolescentes no Brasil, 2011 a 2017. Boletim Epidemiológico, 49 (27), 2018.

ORTNER, Sherry B. "Está a mulher para o homem assim como a natureza para a cultura?”. In: ROSALDO, Michelle Z. LAMPHERE, Louise (orgs.). A mulher, $a$ cultura, a sociedade. Rio de Janeiro: Paz e Terra, 1979. pp. 95-120.

OVERING, Joanna. Estruturas elementares de reciprocidade: o pensamento político nas Guianas, Brasil Central e Noroeste amazônico. Cadernos de Campo, 10 (10), 2002.

RIVIÉRE, Peter. A predação, a reciprocidade e o caso das Guianas. Mana, 7 (1), 2001.

RUBIN, Gayle. O tráfico de Mulheres: notas sobre a "economia política" do sexo. Recife: S.O.S. Corpo, 1993.

SAFIOTTI, Heleieth. Contribuições feministas para o estudo da violência de gênero. Cadernos Pagu, 16 (1), 2001. 
VERNIER, Bernard. Théorie de l'inceste et construction d'objet: Françoise Héritier, la Grèce antique et les Hittites. Annales. Histoire, Sciences Sociales, 51 (1), 1996.

VERNIER, Bernard. Les Suppliantes d'Eschyle et l'incest. L'homme, 2008

VIVEIROS DE CASTRO, Eduardo. A inconstância da Alma Selvagem. São Paulo: CosacNaify, 2002.

VIVEIROS DE CASTRO, Eduardo. Atualização e contra-efetuação do virtual na socialidade amazônica: o processo de parentesco. Ilha - Revista de Antropologia, 2 (1): 5-46, 2000.

WIGGERS, Raquel. Família em conflito: violência, espaço doméstico e categorias de parentesco em grupos populares de Florianópolis. Dissertação apresentada no Programa de Pós-Graduação em Antropologia Social da Universidade Federal de Santa Catarina, Santa Catarina, 2000.

WIGGERS, Raquel. "Sou daqui da Caieira da Barra do Sul”: parentesco, família, casa e pertença em uma localidade no sul do Brasil. Tese de Doutorado em Ciências Sociais, Unicamp, 2006. 